\title{
O Outro e a arquitetura da cidade: as relações de poder em Um lugar ao sol
}

\author{
Maria Helena Braga e Vaz da Costa \& Wendell Marcel Alves da Costa*
}

Resumo: O objetivo deste trabalho é compreender como o discurso sobre a classe alta brasileira, que mora em apartamentos de cobertura, é construído no documentário Um lugar ao sol (2009), de Gabriel Mascaro. Afere-se que o pensamento da elite brasileira é reproduzido no imaginário relacionado aos problemas sociais e espaciais; ou seja, este imaginário se consolida por meio da verticalização da paisagem urbana, da violência e do medo nas cidades, e nas relações de poder entre as classes sociais. A partir da análise de Um lugar ao sol, pretende-se evidenciar como novas configurações de sociabilidade surgem no contexto simbólico referente à moradia da elite.

Palavras-chave: cinema documentário; arquitetura; relações de poder; desigualdade social.

Resumen: El objetivo de este trabajo es entender cómo se construye el discurso sobre la clase alta brasileña, que vive en "apartamentos de cobertura" (áticos), en el documental Um lugar ao sol (2009), de Gabriel Mascaro. Se observa que el pensamiento de la élite brasileña es reproducido en el imaginario relacionándolo con los problemas sociales y espaciales; es decir, dicho imaginario se consolida a través de la verticalización del paisaje urbano, de la violencia y del miedo en las ciudades, y en las relaciones de poder entre las clases sociales. A partir del análisis de Um lugar ao sol, se pretende mostrar como surgen nuevas configuraciones de sociabilidad en el contexto simbólico referente a la vivienda de la élite.

Palabras clave: cine documental; arquitectura; relaciones de poder; desigualdad social.

Abstract: This paper aims to understand how the film discourse about the Brazilian high class, that live in coverage apartments, is built in the documentary Um lugar ao sol (2009), by Gabriel Mascaro. We comment that Brazilian elites' thinking is reproduced in the imaginary related to social and spatial problems; that is, this imaginary is consolidated through the verticalization of the urban landscape, violence and fear in the cities, and in power relations between social classes. From the analysis of $U m$ lugar ao sol, we try to evidence how new configurations of sociability arise in the symbolic context concerning the dwelling of the elite.

Keywords: documentary cinema; architecture; power relations; social inequality.

* Maria Helena Braga e Vaz da Costa: Universidade Federal do Rio Grande do Norte - UFRN, Departamento de Artes. 59025, Natal, Brasil. Bolsista de Produtividade em Pesquisa do CNPq. E-mail: mhcosta.ufrn@gmail.com

Wendell Marcel Alves da Costa: Mestrando em Antropologia Social, Universidade

Federal do Rio Grande do Norte - UFRN, Departamento de Antropologia Social. E-mail: marcell.wendell@hotmail.com

Submissão do artigo: 08 de outubro de 2016. Notificação de aceitação: 16 de dezembro de 2016

Doc On-line, n. 21, março de 2017, www.doc.ubi.pt, pp. 97-113. 
Résumé: L'objectif de ce travail est de comprendre comment le discours sur la classe supérieure brésilienne, qui vit dans des appartements de grand standing, est construit dans le documentaire Um lugar ao sol (2009), de Gabriel Mascaro. Il se base la pensée de l'élite brésilienne qui joue avec un imaginaire lié à des problèmes sociaux et spatiaux; c'est dire que cet imaginaire est renforcé par l'intégration verticale du paysage urbain, la violence et la peur dans les villes, et dans les relations de pouvoir entre les classes sociales. L'analyse de Um lugar ao sol est destinée à montrer comment de nouveaux paramètres de sociabilité apparaissent dans le contexte symbolique se référant au logement d'élite.

Mots-clés: film documentaire; architecture; relations de pouvoir; inégalité sociale.

\section{Introdução}

Um lugar ao sol (Gabriel Mascaro, 2009) é um exemplo cinematográfico que se destaca no cenário das obras de documentários que lidam com o tema da produção do espaço urbano da cidade no contexto do cinema e que discute de forma direta a respeito das distinções entre as classes sociais brasileiras, a paisagem urbana em que vivem essas classes sociais e a violência da/na cidade.

A proposição analítica realizada nesse trabalho considera e identifica $U m$ Lugar ao Sol como um filme que, desde o seu lançamento, abriu possibilidades para que outros cineastas discutissem sobre a especulação imobiliária e a atualidade das relações de poder entre as classes sociais no Brasil. Como objeto de análise, Um lugar ao sol cumpre o papel de permitir aos leitores e espectadores possibilidades de leituras e discussões críticas sobre os desafios apresentados e representados no discurso fílmico dos entrevistados que são os protagonistas dos filmes: a elite brasileira que vive em apartamentos de cobertura.

O discurso fílmico construído em Um lugar ao sol preconiza uma análise de como a elite brasileira que vive em coberturas têm uma imagem de si. É por isso que destacamos, num certo ponto do trabalho, a fala dessas pessoas. A relação entre as categorias de "alto" e "baixo", "dentro" e "fora", "convidado" e "intruso", "sujeito" e "indivíduo", "eu" e "Outro", são dimensões características da construção das novas arquiteturas e arranjos espaciais que identificam os "modelos" de (con)viver com as outras pessoas na sociedade contemporânea. A produção do espaço, e conseguintemente, a transformação das paisagens urbanas e sociais das cidades brasileiras, no filme são representadas pela construção de uma narrativa singular quando potencializa a contraposição daqueles que estão "no alto" ("Alto", "Dentro", "Convidado", "Sujeito", "Eu", com Identidade), frente aqueles que estão "na rua" ("Baixo", "Fora", "Intruso", "Indivíduo", "Outro", sem Identidade). 
É a partir dessas relações dicotômicas que o filme apresenta os resquícios da colonialidade na sociedade brasileira. O que destacamos, desse contexto, são as relações de poder existentes nos processos de sociabilidade, visto que o capital (simbólico e cultural) pode ser considerado como diferenciador social da estruturação das classes sociais.

\section{Documentário, narrativas e classes sociais}

Recentemente, o documentário brasileiro contemporâneo se vale de temas que envolvem o "jogo" de classes sociais e as relações de poder na sociedade atual. Se hoje existem novas formas de (con)viver em sociedade, produzindo assim novas formas de sociabilidades no espaço urbano, os filmes documentários investem parte de suas produções na tentativa de compreender como os fenômenos sociais estão acontecendo no âmbito da cidade - esse é, pelo menos, o caso de Um lugar ao sol.

Atualmente, o cinema pernambucano tem retratado e discutido os diferentes modos de viver em sociedade. Nesse sentido, a construção fílmica do espaço urbano recifense é comumente percebida como um dispositivo, um arquétipo, por meio de sua representação arquitetural das mudanças sociais da vida urbana das grandes cidades. A cidade contemporânea é um imperativo simbólico oriundo da relação de diferentes dispositivos que comunicam e dão sentidos a ela: a paisagem, o espaço, o lugar e os indivíduos que nela vivem e circulam produzindo práticas e papéis sociais.

As mudanças podem ser percebidas nos diversos espaços da metrópole, e a cidade e seus desenhos sociais e culturais tornam-se reflexo dos desafios e conflitos trazidos pelo processo vigente do intenso desenvolvimento econômico ocorrido nas regiões do país, como apresentado em Um lugar ao sol (Figura 1). 


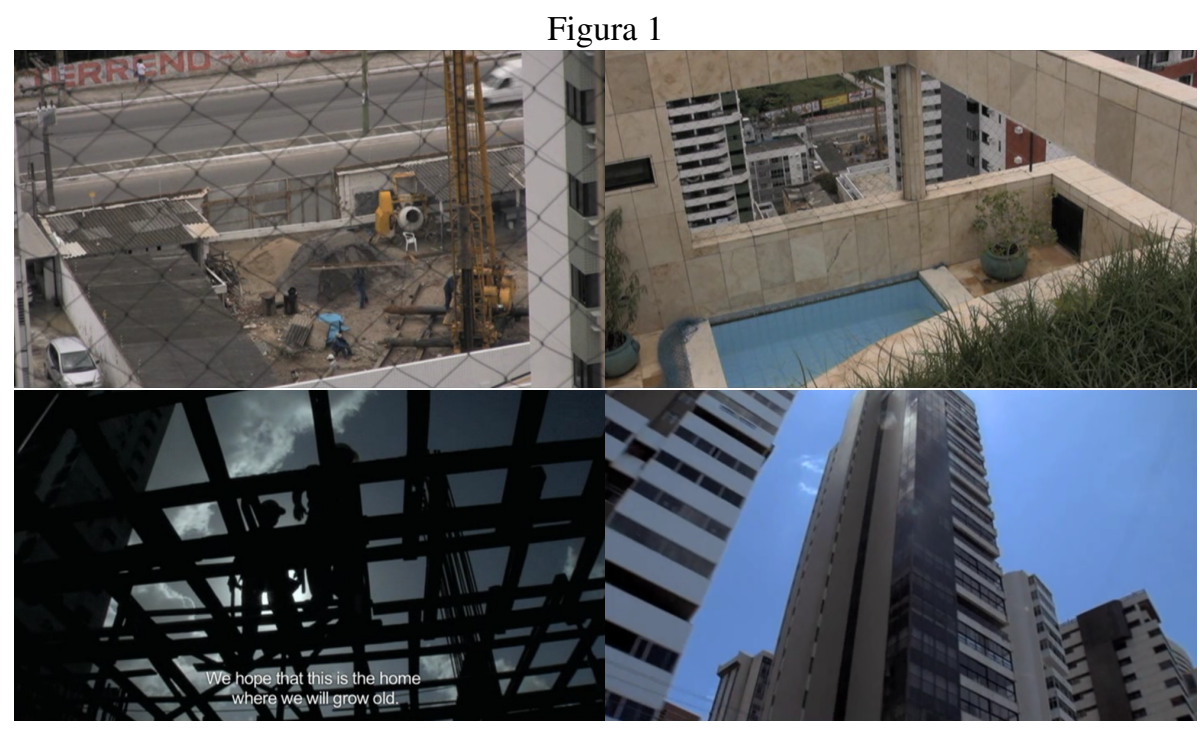

As cidades estão se tornando cada vez mais verticalizadas e a comunicação entre as pessoas sofre mudanças em todos os níveis da linguagem. A sensação de estar na cidade dá lugar a fobias cada vez mais arraigadas nos sujeitos que nela vivem, começando pelos mais jovens que se divertem aprisionando-se nos shopping centers; os mais velhos, por sua vez, se negam a transitar pela urbe poluída visualmente e sonoramente. Aqui, pode-se contextualizar o filme em uma discussão não apenas local, mas em um discurso mais amplo sobre os processos de verticalização e expansão urbanas que têm ocorrido em diversos países do mundo. Ademais, associa-se a esse processo a questão da violência urbana, que não se tornou prerrogativa de um único país.

Como cita Lapa (2011: 78-79), sobre a verticalização das construções residenciais no cenário internacional:

Apesar de que a inserção de arranha-céus pode representar uma ameaça à silhueta tradicional dos centros históricos, a ideologia de fazer crescer verticalmente as cidades impõe-se cada vez mais. [...] Mesmo em países que conservaram importantes centros históricos, os espaços urbanos tradicionais tornam-se o objeto da cobiça dos promotores urbanos que constroem tipos arquitetônicos cuja escala urbana não é compatível com o espírito do lugar.

São exemplos efetivos da representação do tema, por exemplo, os filmes brasileiros Aquarius (Kleber Mendonça Filho, 2015), O som ao redor (Kleber Mendonça Filho, 2012), Febre do rato (Cláudio Assis, 2012), Rio doce/CDU (Adelina Pontual, 2011) entre outros. Esses filmes se estruturam de modo a apresentar as paisagens da cidade do Recife como um espaço que sofre in- 
tensas transformações relacionadas ao espaço de convivência corporificada essencialmente pela verticalização das moradias e o conseqüente aparecimento de novas configurações do conviver/viver com o Outro. Evidentemente, estão postas nas narrativas desses filmes temáticas ligadas às relações de poder, de empoderamento, das classes sociais, e das representações do espaço urbano e capital simbólico presentes na vida cotidiana.

Dessa forma, os filmes de gênero documentário produzem narrativas que olham para, e se preocupam com a discussão sobre a construção do Outro, e as problemáticas envolvidas nas relações de poder presentes no "jogo" das classes sociais. A linguagem do documentário constrói seu discurso, portanto, por meio da enunciação de códigos e símbolos originários nos discursos envolvidos nas relações de poder entre as classes sociais. O objeto do Outro, logo, insere-se como um elemento central da relação de poder envolvida entre as classes sociais, principalmente por que ele apresenta-se como um símbolo personificado da conseqüente estratificação social que constitui a formação da sociedade brasileira contemporânea.

A leitura que fazemos sobre a cidade é de um complexo fenômeno moderno que origina diferentes modos de operações socioespaciais no campo da sociabilidade entre os sujeitos envolvidos nos processos comunicacionais. Levamos em consideração que a cidade pode ser um ambiente de reconhecimento do espaço (De Certeau, 1998), comunicação e construção de variáveis percepções sobre o espaço arquitetural (Canevacci, 2004) e de trajetos, composições, significações e operações simbólicas regidas por sociabilidades delimitadas pelo espaço urbano da metrópole (Magnani, 2008).

O discurso sobre o espaço urbano e suas formas, compreende o imaginário acerca das diferentes ações de manter contato com o Outro no espaço da cidade, imperializando sentidos de confinamento nos locais de lazer e de moradia. Por esta lógica, se constitui a noção de que a cidade é, em essência, regida pela violência e pelo medo de que, a qualquer momento, a privacidade seja neutralizada por forças externas, ou seja, pelo Outro.

Definitivamente, o Outro é o indivíduo que representa o medo inerente aos processos interacionais entre os sujeitos que habitam e/ou circulam nas grandes metrópoles contemporâneas. Em uma época de intensas reflexões culturais e sobre o sentido do lugar comum, o Outro significa o medo do que é diferente ou do desconhecido, comportando as lógicas de diferenciação entre as camadas sociais historicamente estratificadas por categorias econômicas.

Assim, a partir da relação entre o Outro - que é o indivíduo na perspectiva do sujeito, ou seja, da classe alta brasileira - e o sujeito - que é o personagem central da análise de Um lugar ao sol - o "jogo" simbólico das classes 
sociais traduzem os desafios de uma sociedade permanentemente desigual socialmente. Podemos afirmar, assim como Bauman (2009), que "a insegurança moderna, em suas várias manifestações, é caracterizada pelo medo dos crimes e dos criminosos. Suspeitamos dos outros e de suas intenções, nos recusamos a confiar (ou não conseguimos fazê-lo) na constância e na regularidade da solidariedade humana" (Bauman, 2009: 14).

Então, em vista do exposto, entendemos que o discurso fílmico trabalha essas questões sobre segurança e medo na cidade, e percebemos na arquitetura urbana a indicação de uma intensa diferenciação entre as classes sociais no país. A construção do discurso fílmico sobre o tema das relações de poder e das classes sociais se estabelece de forma difusa nos filmes documentários.

Se o documentário insere personagens da vida real na paisagem do espaço fílmico, o espectador de cinema pode entender que aqueles personagens são reais e que os seus discursos são, em suas totalidades, verídicos. Contudo, é próprio da linguagem do gênero documental construir um discurso dialógico sobre um tema específico, pensando não apenas na passagem conflitante inerente à discussão do tema como também na incorporação de falas distintas a respeito de um mesmo efeito problematizado, discursivo e paradigmático. Nesse contexto, Gauthier (2013) e Campo (2015) destacam a importância do gênero documentário:

Não porque é mais verdadeiro que a ficção, ou melhor documento, mas porque testemunha uma sequiência vivida anteriormente. A esta sequiência, posso destacá-la, pulverizá-la, fazê-la participar de um discurso que conduz à progressão, negar sua singularidade para atuar unicamente sobre sua capacidade metafórica. (Gauthier, 2013: 6-7).

$\mathrm{O}$ documentário tem sido um dos principais canais do discurso e da retórica política e que, por outra parte, tem uma porcentagem significativa de filmes documentais que tem apresentado conceitos, problemáticas e posturas políticas de forma mais ou menos sutil. (Campo, 2015: 15).

Por outro lado, o documentário incorpora discursos proferidos por pessoas reais na composição do seu discurso fílmico, e essas mesmas pessoas são personagens/personas em uma dada realidade social, ou mais comumente, em um evento social inserido em uma determinada dinâmica social cotidiana. Eventualmente, as pessoas representam papéis e são transmissores de discursos (Goffman, 1985); a diferença é que no âmbito fílmico essas pessoas/personagens da realidade social também produzem comportamentos que não teriam uma significância maior no âmbito real.

Sendo assim, podemos considerar o documentário como uma maneira de observar uma dada realidade e o que é filmado se constitui em uma corporali- 
dade fílmica, isto é, aquilo que se refere à representação dos sujeitos na cena do espaço do documentário. Logo:

Dentro desta dinâmica de relações pautada pelo fetiche da imagem como certificado de existência, ter uma câmera apontada para si tornou-se um "privilégio ontológico" gerador de uma ansiedade exibicionista. Impôs-se o "efeito câmera" como elemento que estrutura certas situações em que é inevitável a teatralidade, o pequeno (ou grande) jogo social onde cada qual assume um papel - ou imagem - dentro de novas modalidades de convívio geradas pelo olhar dos aparelhos. (Xavier, 2015: 229).

Essa corporalidade fílmica no gênero documentário é construída pelas narrativas que organizam os discursos proferidos durante a filmagem. É através desse reordenamento que o sentido filosófico do filme se constrói. No documentário, "as chaves de sua originalidade se confirmam na busca de novas estruturas formais através de diversas estratégias narrativas e estéticas", no entanto, "o problema da viabilidade da representação do documentário é de um eixo impossível de ser captado por um meio técnico: o pensamento" (Vallejo, 2013: 5-21).

Em resumo, é o discurso, e num movimento mais amplo, o pensamento da classe alta que vive nas elegantes e caras coberturas de três cidades brasileiras (Recife, Rio de Janeiro e São Paulo), o objeto de análise a partir do filme Um lugar ao sol. Constata-se que o pensamento da elite brasileira reproduz o imaginário desse grupo sobre alguns dos problemas sociais apresentados de forma contundente pelos veículos de comunicação em massa.

No sentido de compreender, a partir das reflexões sobre o sentido do documentário e a sua potência imagética em conceber uma imagem carregada de intencionalidade, devemos refletir sobre a construção das narrativas fílmicas, e desconstruir o seu discurso.

A análise das narrativas cinematográficas são interpretações que visam entender como o discurso é construído no filme, isso porque, analisar um filme é examiná-lo tecnicamente (Vanoye, 1994), para só então decupá-lo simbolicamente, semioticamente, discursivamente e esteticamente. As narrativas produzem sentidos efetivos sobre a dada realidade que está sendo retratada, sendo "possível utilizar o filme com o intuito de analisar uma sociedade" (Vanoye, 1994: 55).

Num sentido mais geral:

A narrativa cinematográfica não é a representação ou o relato de um acontecimento, não é "uma janela aberta para o mundo", como queria André Bazin, nem uma ponte para o mundo interior, feito de desejos e fantasias insatisfeitos, como quer a psicanálise "aplicada" ao cinema. A narrativa cinematográfica é o próprio acontecimento, o lugar entre o modo como o acontecimento constitui a narrativa e a narrativa constitui a realidade. É esta mínima distância que 
precisa ser percorrida pelo pensamento analítico, porque é nesta fronteira que circula o pensamento fílmico, é nela que o pensamento é chamado a produzirse. O pensamento analítico é, portanto, o movimento que acompanha o filme para reduplicá-lo. (França, 2003: 114).

E no âmbito das representações, pensando as relações de poder e o "jogo" entre as classes sociais, acreditamos também que:

O cinema mostrou que, de todas as artes, é a mais política, justamente porque, arte da mise-en-scène, sabe destacar as mise-en-scènes dos poderes dominantes, assinalá-las, sublinhá-las, esvaziá-las ou desmontá-las, se necessário rir delas, fazer transbordar seu excesso na perda. (Comolli, 2008: 63).

Evidenciamos também que o documentário, sobretudo a produção latinoamericana, se insere como um importante dispositivo de relevância social sobre problemas sociais e políticos vigentes no âmbito da América Latina. Neste continente, o documentário surge como uma ferramenta por meio do qual os cineastas podem apresentar distintos olhares acerca das realidades sobre os temas: desigualdade social e de gênero, violência, direitos humanos, crises políticas e econômicas, racismo e pós-colonialidade, entre outros. Em vias de expressão, a proposta que se apresenta nos filmes documentários latinoamericanos é de fugir da visão do estrangeiro, que imperializa um olhar e um discurso carregado de violência e controle simbólico sobre as práticas, os costumes, os conflitos e as persistências históricas de violência na América Latina (Shotat, Stam, 2006; Amâncio, 2000).

Diante disso, embora as narrativas possibilitem construir um discurso no sentido de perceber um objeto a partir de um olhar específico, a subjetividade imposta nessa construção simbólica da imagem também posiciona o nosso ponto de visão em uma posição unilateral sobre o objeto filmado/analisado. Sendo assim, não se pode obscurecer o que seria impossível de ser visto no objeto filmado, podendo ele igualmente contribuir com outras leituras do tema como as classes sociais e as relações de poder entre os moradores de coberturas residenciais que tem o Outro como indivíduo eminentemente ameaçador no espaço urbano.

Diferentes leituras falam da reestruturação do espaço urbano da cidade ao lado da gentrificação imposta por ela (Smith, 2007), o que pode ser entendido através das mudanças trazidas pelas novas formas de comunicação na contemporaneidade. $\mathrm{Na}$ atualidade, os sujeitos se comunicam por meio de dispositivos móveis, e o contato físico pouco se dá através da interceptação direta pela visão objetiva. Os lugares da cidade (praças, becos, ruas, etc.) estão sofrendo atualizações em seus conceitos definidores dos sentidos afetivos sobre a espacialidade social do lugar, podendo agora se organizar em locais privados, como os complexos residenciais (comunidades montadas para comportar famílias in- 
teiras num simulacro de bairro residencial com ruas e parques próprios), e em edifícios que possuem o controle rígido da segurança do lugar e das pessoas que entram e saem do local. Câmeras vigiam cada passo dos moradores e dos visitantes nos corredores e escadas e nos locais de lazer do edifício. ${ }^{1}$

Entendido isso, é no movimento de fugir ou se afastar da violência da cidade que as pessoas buscam locais onde possam conviver tranquilamente com o Outro, sem precisarem ter contato direto com ele. O edifício residencial representa esse sentimento, que está se tornando cada vez mais forte e uniforme nas cidades contemporâneas. A imagem da paisagem urbana apresenta as inúmeras construções que verticalizam o nosso olhar sobre o espaço urbano das cidades: os edifícios cada vez mais altos e "seguros" que concedem novos sentidos à noção de lar e de casa.

\section{"Do alto eu vejo tudo": a arquitetura e as relações de poder}

A conjunção entre as linguagens do cinema e da arquitetura nos leva a perceber certas nuances nas cidades contemporâneas. Ambas as formas produzem um discurso singular sobre como se apresentam os desenhos espaciais de uma perspectiva histórico-cultural e como o indivíduo é situado nesse contexto.

Na tentativa de compreender como o espaço urbano das cidades se organiza (ou se reestrutura) nas lógicas de sociabilidade e de comunicação na contemporaneidade, a nossa análise identifica os sentidos da arquitetura como formas de representação simbólica e conceitual projetada na paisagem urbana. A arquitetura não é apenas uma expressão geométrica e concreta de uma forma, com uma função pensada e aplicada no projeto arquitetônico, é também um trabalho regido por concepções sobre a valorização do espaço com uma delimitação do poder do indivíduo que possui o espaço construído e transformado para os seus devidos fins de habitação.

A construção do sentido na arquitetura leva em consideração algumas formalidades conceituais e simbólicas. Está envolta em aspectos relacionados aos contextos políticos e históricos das cidades, onde a arquitetura esteve/está presente em seus processos de significação particulares. O arranjo espacial é importante, já que repercute no âmbito das comunicações e das sociabilidades que se dão no espaço, gerando oposições/diferenciações entre as classes sociais (Figura 2).

1. Edifício Master (Eduardo Coutinho, 2002), filme emblemático da produção de documentário no Brasil, identificou esses processos no âmbito da vivência privada em um edifício no Rio de Janeiro. Entendendo esse espaço como uma organização social, com suas regras e sentidos simbólicos próprios, o diretor investiga o imaginário de viver em um ambiente privado/coletivo. 
Figura 2

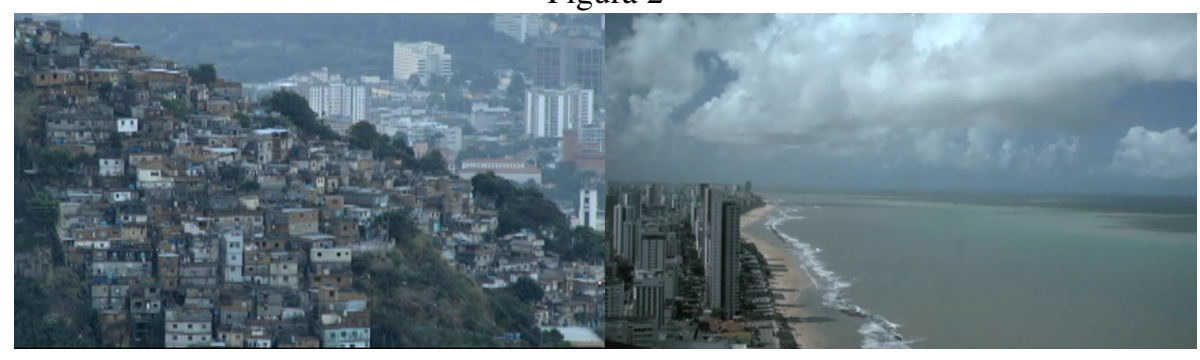

Aqui abordados, os sentidos produzidos pela intervenção da arquitetura na produção do espaço social se dão em três eixos de contraposição: espaço interior e espaço exterior; espaço privado e espaço comum; e espaço vertical e espaço horizontal (Coelho Netto, 2012).

Nossa proposta teórico-metodológica é direcionada a partir desses três eixos em conformidade ao discurso do filme Um lugar ao sol, sem desvencilharmo-nos do discurso do espaço arquitetural produzido pela elaboração do arranjo espacial, nem do discurso fílmico do espaço arquitetônico habitado pelos moradores das coberturas residenciais.

O primeiro dos eixos, espaço interior e espaço exterior, nos leva a indagações sobre os significados dos conceitos de casa e lar. Como se afere do documentário Um lugar ao sol, o sentido de lar é corriqueiramente adequado para se referir ao edifício em que se mora, portanto revelando um espaço interior altamente carregado de afetividade. O lugar é, antes de tudo, uma morada e tem um aspecto comum entre os indivíduos: significa um ambiente onde esses indivíduos se sentem à vontade e despreocupados com as vicissitudes da vida "lá fora"; ou seja, aquelas do espaço exterior, e, conseguintemente, do espaço do Outro.

Consideremos algumas questões sobre as identidades do Outro e do sujeito a partir dos sentidos de espaço interior e espaço exterior. O Outro é o sujeito entendido aqui como indivíduo fragmentado em diferentes contextos de comunicabilidade nas relações entre as classes sociais. Esse sujeito - na interação social com um sujeito de capital simbólico e cultural elevado reduz-se a indivíduo - pode ser considerado como o "visitante" no espaço de convivência/lar, porque é um indivíduo que foi convidado a entrar no âmbito do privado, contudo, não é efetivamente aceito nas relações sociais e é considerado, dentro das normas e códigos dos contratos sociais, não possuidor de capital simbólico. $\mathrm{O}$ Outro é um indivíduo sem identidade (Figura 3), aquele que está nos lugares suburbanos e periféricos, e é visto como aquele despossuído de capital cultural e econômico. O Outro é, efetivamente, como podemos verificar em Um lugar 
ao sol a representação corporificada do medo na metrópole contemporâneaindustrial-capitalista.

Figura 3

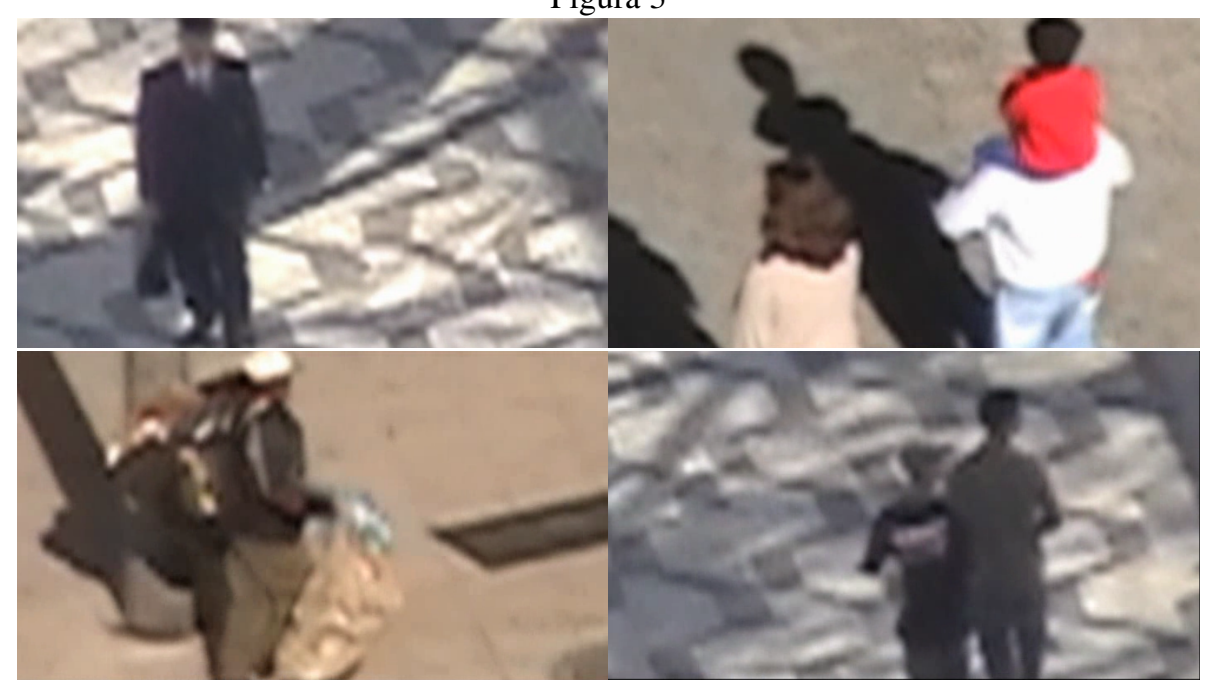

Embora a prática de receber visitantes no lar/cobertura seja costumeira para alguns moradores das coberturas, a intimidade é resguardada, pois, para quem vive no local mais alto dos edifícios, a impressão e certeza é a de que se detém o privilégio de se distanciar dos inconvenientes da cidade, dos barulhos da rua, das festas dos vizinhos, enfim, do Outro. A intimidade proporcionada pela cobertura é o ponto-chave na questão do espaço interior da arquitetura da cobertura, e esse tipo de residência representa simbolicamente uma escolha: fuga da realidade da cidade. Viver em uma cobertura, como podemos inferir a partir do filme, é adquirir um espaço diferenciado, resguardado e íntimo: o som da cidade não adentra as coberturas; e o som interno pode ser controlado mediante a escolha do morador.

O controle interno do som na cobertura residencial encontra uma particularidade em Um lugar ao sol, quando em uma das cenas a entrevistada refere-se ao "não ouvir" o "bater das panelas" na cozinha. O fato de a cobertura residencial ser planejada arquitetônicamente/espacialmente em dois ambientes difere as pessoas que estarão circulando pelo ambiente da cobertura, categorizando assim posições e funções no âmbito do lar: as pessoas que trabalham na cobertura e as pessoas que moram na cobertura.

Nesse ponto, o espaço privado e o espaço comum têm se relacionado na categoria da situação econômica que interfere diretamente no tipo do espaço 
privado, refletindo o "jogo" de classes e a privatização do espaço urbano comum. Os sentidos culturais e históricos explicam essa relação, na direção de que a dicotomia das diversas esferas políticas e econômicas salienta as diferentes maneiras de se organizar socialmente.

Para Caldeira (1997), as cidades e as configurações do espaço privado vêem se reestruturando nas cidades contemporâneas. Analisando o caso da cidade de São Paulo, a autora percebeu que os "ajustamentos" de moradia se transformaram em fortificações privadas, motivados pela intensa propagando do "viver bem" em edifícios super protegidos e contidos no imaginário da cidade que tem como estrutura social a violência como propulsor da sensação de medo.

A consequência gerada por esse movimento social (na questão das classes sociais) e econômico (no quesito da desigualdade econômica na sociedade brasileira) resulta em uma segregação espacial entre aqueles que restringem uma parcela tanto quantitativa quanto qualitativa do espaço urbano. $\mathrm{O}$ resultado desse processo é o surgimento de guetos e lugares periféricos, onde são alocadas as pessoas despossuídas de territórios comuns e que são privados do centro da cidade ou das regiões mais valorizadas pelas empresas imobiliárias de alto rendimento.

De acordo com Coelho Netto (2012), o espaço vertical e o espaço horizontal possuem sentidos tanto metafóricos quanto simbólicos na compreensão dos arranjos espaciais da arquitetura. A imagem que temos é essa: o sótão pode significar o local que protege, que é superior no espaço do lar, e, em síntese, ser racionalista na ótica da posição verticalizada do ambiente. Ao contrário deste, o porão revela as profundezas, o que é inferior e irracional. A expressão da verticalidade pode apresentar vias de inferioridade e superioridade, mistério e revelação, o que protege ou é protegido, o que provoca medo ou traz a falta de proteção. As categorias dicotômicas de "no alto" ("Alto", "Dentro", "Convidado", "Sujeito", "Eu", com Identidade) e de "na rua" ("Baixo", "Fora", "Intruso", "Indivíduo", "Outro", sem Identidade) são perpendiculares às noções dos espaços vertical e horizontal, no sentido de que o lugar de moradia da elite brasileira representa a construção espacial das diferenças entre os sujeitos na sociedade brasileira. Admite-se, nesta ordem de entendimento do problema social aqui discutido, tendo em vista o discurso social representado em Um lugar ao sol, produzido pelos entrevistados, as nuances simbólicas destas categorias para a interpretação da realidade social brasileira. 
Dessa forma, indicadas essas posições ${ }^{2}$, entende-se que o documentário Um lugar ao sol realça os diferentes olhares das pessoas que moram nas coberturas, sobre aqueles que circulam nas ruas, avenidas e lugares da cidade. A diferenciação social por meio do discurso dos entrevistados está posto: a visão daqueles que moram nas coberturas sobre os que não moram nelas. As significações a partir dos discursos dos entrevistados abrem possibilidades para o entendimento de como o capital econômico, e simbólico, é fortemente influenciador em sua construção discursiva: "eu sempre morei olhando para cima" (pertinho do céu; consegue ver as coisas bonitas da cidade por um ângulo diferenciado); "viver na cobertura dá a sensação de dominar o espaço"; e "quando você quer ter a cobertura você usa a cobertura". ${ }^{3}$ A expressão "balas tracejantes" que aparece na fala do casal que mora em uma cobertura na cidade do Rio de Janeiro, de frente à comunidade (favela) Dona Marta (que segundo uma entrevistada mais parece "caixinhas de brinquedo"), fecha um círculo em torno do filme que é o seguinte: viver nas alturas é ter o privilégio de não ver, nem viver, a violência (ela torna-se auditiva e não mais visual), mesmo sabendo que ela existe a $1 \mathrm{~km}$ de distância.

Neste momento chegamos a um ponto crucial no filme, em que a relação de poder se põe implícita nas falas dos entrevistados de Um lugar ao sol. As imagens "claustrofóbicas" dos espaços exteriores contrastando com as das coberturas intensificam a diferença entre o morador da cobertura e o Outro. Se "o poder é um prazer muito bom", como destaca um dos entrevistados, e morar em uma cobertura é possuir um tipo de poder (aquisitivo, social, simbólico), só resta para aqueles que não o possuem viver sob a sombra daqueles que detém o poder (Figura 4). Em suma, morar em uma cobertura é ser privilegiado, é morar mais perto do sol.

2. Logo, pode-se concluir que a construção do sentido na arquitetura está relacionada a diversos fatores que acometem a produção do espaço de forma subjetiva (estética, social e política) e objetiva (desenhos, formas e ângulos).

3. No que indica o antropólogo DaMatta (1997), a expressão "sabe com quem está falando?" não reduz o seu significado às relações de poder presentes na utilização consciente do capital econômico em certos eventos e contratos sociais cotidianos. Pelo contrário, a expressão ressignifica os tratamentos entre as classes sociais e a efetiva nomenclatura originada a partir da herança colonial brasileira. 


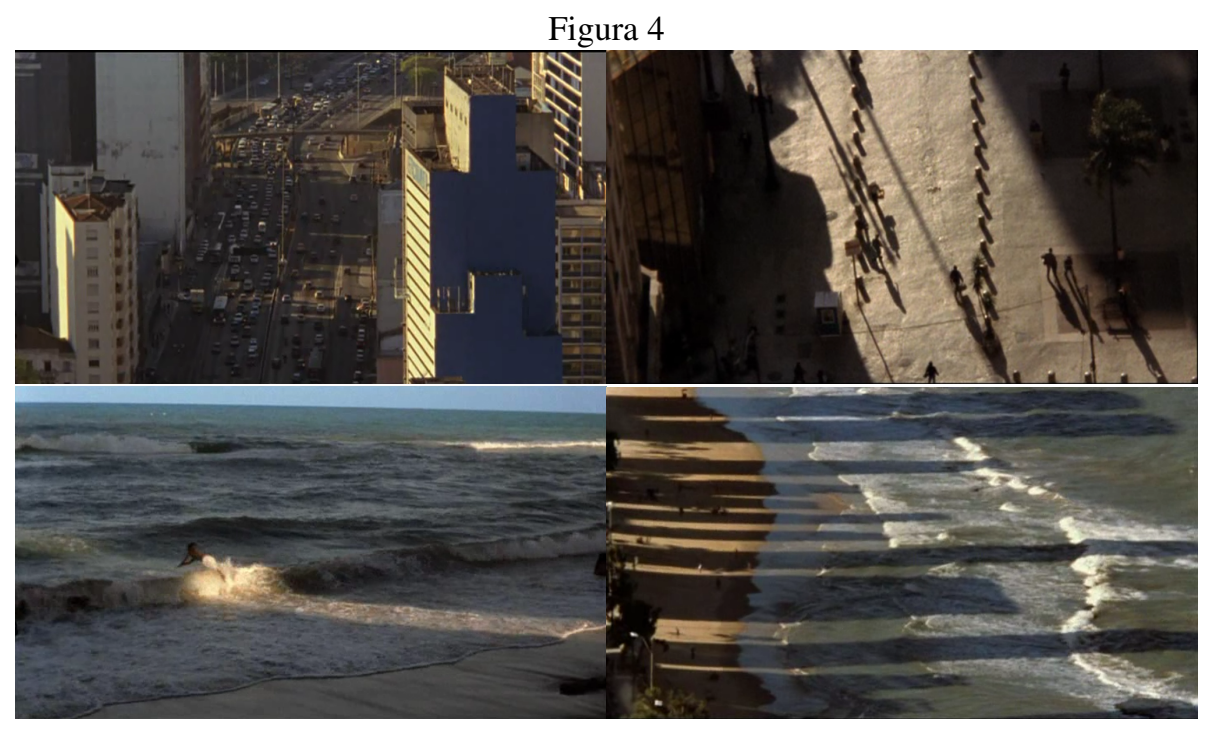

Na cidade do Rio de Janeiro, as paisagens urbanas possuem significativamente uma importância imagética na ordem do discurso quando tratadas na relação com os edifícios residenciais que estão presentes nos contornos do espaço urbano. Em certo momento, temos a exibição de uma gravação realizada por uma das entrevistadas, que filma a cidade e o seu principal cartão-postal, o Cristo Redentor (Figura 5). As cenas são reveladoras, assim como a fala da entrevistada, que apresenta ao espectador uma "bela" cidade, que compartilha do mesmo espaço com a "comunidade Dona Marta", que segundo ela, "desmata" a vegetação sem nenhuma preocupação ambiental.

Em outro plano, a personagem enquadra a cidade do Rio de Janeiro em sua extensão paisagística até o horizonte onde se podem ver algumas montanhas. O que nos chama atenção aqui é que a imagem filmada do horizonte, na profundidade de campo, é fraca e pouco se consegue ver por causa da evidente poluição da cidade carioca. O caminho até o horizonte é acompanhado por inúmeros prédios, arranha-céus e carros na parte inferior do quadro. Contudo, a entrevistada não se preocupa com a paisagem urbana que desgasta a paisagem natural do Rio de Janeiro. Diante disso, podemos afirmar que o olhar torna-se viciado sobre a cidade na lógica da passagem do tempo, incorporando a paisagem transformada pela urbanização acelerada à paisagem natural. Um sentido mistificado do lugar é sustentado pelas imagens e também pelo discurso da entrevista que nos "apresenta" a cidade através do seu olhar. 
Figura 5

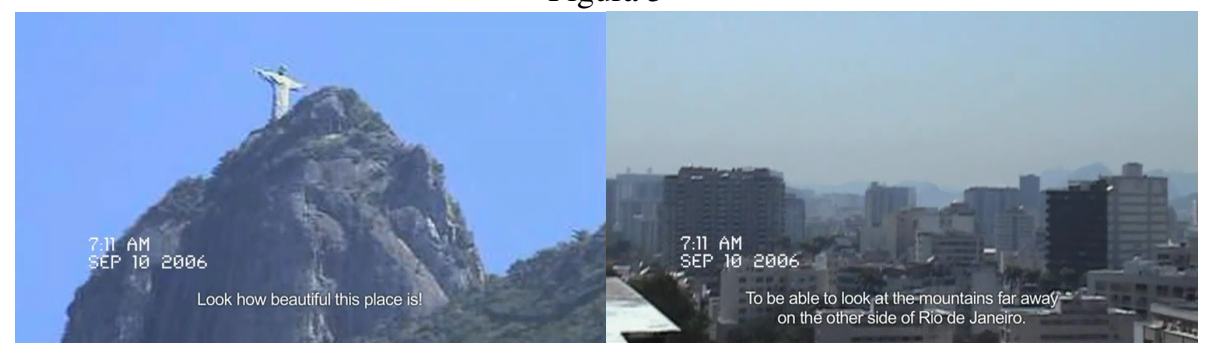

Em outro momento, as imagens da cidade do Recife também inferem proposições sobre o seu significado simbólico e de poder no contexto urbano. A cidade que se transforma a partir da especulação imobiliária, e que visa com isso a posse de territórios para preservar uma identidade cultural da cidade. A perspectiva reside na preocupação com a manutenção arquitetônica, espacial, social e sonora dos lugares da cidade nordestina.

Um lugar ao sol, dessa maneira, reúne em um mesmo dispositivo, temas tão caros na atualidade: espaço urbano e especulação imobiliária desenfreada, a transformação da paisagem da cidade, as relações de poder advindas da estratificação social nas classes sociais, a representação social pela elite brasileira, o poder e o imaginário na/da cidade.

\section{Considerações finais}

Conclui-se que o filme Um lugar ao sol, constrói em seu discurso uma narrativa do espaço urbano e das relações constituídas por aqueles sujeitos que o habitam, e mais particularmente, sob o ponto de vista daqueles que estão no controle simbólico e econômico desse espaço. Semelhante a uma ilha, a cobertura é aquela extensão territorial cercada por águas, inclusive na parte de cima, como defende um dos entrevistados no documentário. A ilha é uma pequena área de terra, que comporta poucos moradores (os selecionados). $\mathrm{O}$ filme, assim, pode ser resumido a essa fala dada como resposta por um dos entrevistados à questão "como é viver em uma cobertura e/ou pra você o que é ter uma cobertura?". O entendimento do discurso dos entrevistados torna-se visual, quando a imagem da ilha figura como uma representação espacial do poder detido pela classe alta da sociedade brasileira.

\section{Referências bibliográficas}

Amâncio, T. (2000). O Brasil dos gringos: imagens no cinema. Niterói: Intertexto. 
Bauman, Z. (2009). Confiança e medo na cidade. Rio de Janeiro: Jorge Zahar Ed.

Caldeira, T. P. R. (1997). Enclaves fortificados: a nova segregação urbana. Novos Estudos, (47): 155-176.

Campo, J. (2015). Cine documental: tratamiento creativo (y político) de la realidad. Cine Documental, (11).

Canevacci, M. (2004). A cidade polifônica: ensaio sobre a antropologia da comunicação urbana. São Paulo: Studio Nobel.

De Certeau, M. (1998). A invenção do cotidiano: artes de fazer. Petrópolis: Editora Vozes.

Coelho Netto, J. T. (2012). A construção do sentido na arquitetura. São Paulo: Perspectiva.

Comolli, J.-L. (2008). Ver e poder. Belo Horizonte: Editora UFMG.

DaMatta, R. (1997). Carnavais, malandros e heróis: para uma sociologia do dilema brasileiro. Rio de Janeiro: Rocco.

França, A. (2013). Terras e fronteiras no cinema político contemporâneo. Rio de Janeiro: 7Letras.

Gauthier, G. (2013). El documental narrativo. Documental/ficción. Revista Cine Documental, primer semestre, (7).

Goffman, E. (1985). A representação do eu na vida cotidiana. Petrópolis: Vozes.

Lapa, T. A. (2011). Grandes cidades constroem-se com edifícios grandes?. Recife: Ed. Universitária da UFPE.

Magnani, J. G. C. (2008). Quando o campo é a cidade: fazendo antropologia na metrópole. In J. G. C. Magnani \& L. de L. Torres (orgs.), Na metrópole: textos de antropologia urbana (pp. 12-52). São Paulo: EDUSP.

Shotat, E. \& Stam, R. (2006). Crítica da imagem eurocêntrica: multiculturalismo e representação. São Paulo: Cosac e Naify.

Smith, N. (2007). Gentrificação, a fronteira e a reestruturação do espaço urbano. GEOUSP - Espaço e Tempo, (21): 15-31. São Paulo.

Vallejo, A. V. (2013). Narrativas documentales contemporáneas. De la mostración a la enunciación. Cine Documental, (7).

Vanoye, F. (1994). Ensaio sobre a análise fílmica. Campinas: Papirus.

Xavier, I. (2015). A teatralidade como vetor do ensaio fílmico no documentário brasileiro contemporâneo. In F. E. Teixeira (org.), O ensaio no cinema: formação de um quarto domínio das imagens na cultura audiovisual contemporânea pp. 226-246. São Paulo: Hucitec. 
Filmografia

Um Lugar ao Sol (2009), de Gabriel Mascaro

Aquarius (2015), de Kleber Mendonça Filho

O Som ao Redor (2012), de Kleber Mendonça Filho

Febre do Rato (2012), de Cláudio Assis

Rio Doce/CDU (2011), de Adelina Pontual

Edifício Master (2002), de Eduardo Coutinho 